See Article page 1963.

\section{Commentary: Dispensing with compliance}

\author{
J. W. Awori Hayanga, MD, MPH, ${ }^{a}$ \\ Norihisa Shigemura, MD, $\mathrm{PhD},{ }^{\mathrm{b}}$ and \\ Pablo Sanchez, MD, $\mathrm{PhD}^{\mathrm{c}}$
}

Extracorporeal lung perfusion may be used to improve metabolic support, extend perfusion times, and potentially optimize organ repair. Hozain and colleagues ${ }^{1}$ recently reported improved perfusion times and enhanced lung recovery using a model of xenogeneic cross-circulation. Human lungs were, in this manner, perfused using swine circulation and regained function. Nevertheless, the findings highlight the metabolic and hormonal limitations of contemporary ex vivo techniques. They also demonstrate the need for improvements in organ support capabilities that will eliminate the need for xenogeneic cross-circulation.

In this article, Takahashi and colleagues ${ }^{2}$ catalog their use of modified ex vivo lung perfusate in a porcine model to achieve stable homeostasis in a bid to extend perfusion time. The contribution is timely and relevant and reflects the efforts of an experienced group of transplant surgeons. The authors used 4 groups of 5 Yorkshire male domestic pigs in keeping with the convention endorsed within previously published works. ${ }^{3-6}$ However, the small sample size engenders the threat of a type 2 error that remains prevalent throughout the article. The authors used a mixed-effects linear regression and predicated the analysis on alterations in dynamic compliance and airway pressure. They selected, somewhat arbitrarily, the value of $15 \mathrm{~mL} / \mathrm{cm}$ $\mathrm{H} 2 \mathrm{O}$ as a cutoff for futility with a rationale that caters perhaps more to convenience than strict pathophysiologic construct.

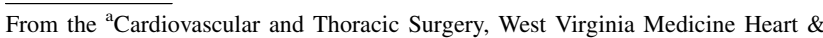
Vascular Institute, Morgantown, WVa; ${ }^{\mathrm{b}}$ Cardiovascular and Thoracic Surgery, Temple University, Philadelphia, Pa; and ${ }^{\mathrm{c} C a r d i o t h o r a c i c ~ S u r g e r y, ~ U n i v e r s i t y ~ o f ~}$ Pittsburgh Medical Center, Pittsburgh, Pa.

Disclosures: The authors reported no conflicts of interest.

The Journal policy requires editors and reviewers to disclose conflicts of interest and to decline handling or reviewing manuscripts for which they may have a conflict of interest. The editors and reviewers of this article have no conflicts of interest.

Received for publication July 28, 2020; revisions received July 28, 2020; accepted for publication July 29, 2020; available ahead of print Aug 3, 2020.

Address for reprints: J. W. Awori Hayanga, MD, MPH, Department of Cardiovascular and Thoracic Surgery, West Virginia University, 1 Medical Center Drive Morgantown, WV 26506 (E-mail: jeremiah.hayanga@wvumedicine.org).

J Thorac Cardiovasc Surg 2021;161:1976-7

0022-5223/\$36.00

Copyright (c) 2020 by The American Association for Thoracic Surgery

https://doi.org/10.1016/j.jtcvs.2020.07.082
}

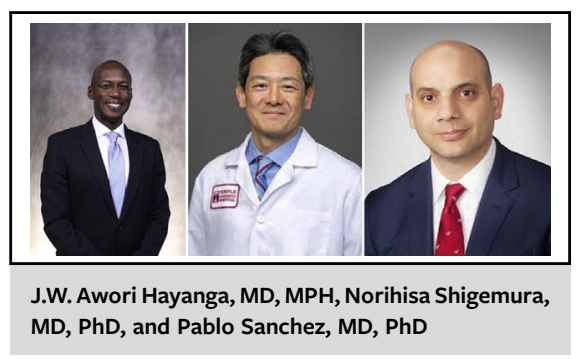

CENTRAL MESSAGE

Extending perfusion times in ex vivo techniques.

For this determination, the authors refer to previously published works in which they investigated the kinetics of lactate metabolism, highlighting the fact that lungs with high lactate/pyruvate ratios demonstrated higher peak airway pressures, lower glucose levels, and higher lactate levels. ${ }^{4}$ There was a significant increase in dynamic compliance in the treatment groups, together with reductions in peak airway pressure and pulmonary vascular resistance, the latter of which distinguishes it from previous reports. ${ }^{7}$ Nevertheless, multiple questions abound. How best can one interpret the observations, considering the use of lungs that had no significant inflammatory injury? Could the difference potentially be the result of a type 1 error?

By their own admission, the authors admit this effect to be an incompletely understood phenomenon, and so it remains unclear how nutritional augmentation contributes to lung preservation. Unmitigated, the ambiguity tempers the enthusiasm and confidence with which the study is received. Furthermore, despite the decrease in cytokine levels within the small sample, it remains unclear which circulating biomarkers best reflect airway inflammation and lung function. As a result, authoritative conclusions must be attenuated somewhat. Nevertheless, the total parenteral nutrition group achieved significantly longer stable perfusion times. Likewise, inflammatory cytokine production was also notably reduced in the continuous replacement group.

Having achieved intravascular delivery of mesenchymal stem cells during ex vivo lung perfusion in an earlier exploration, establishing homeostasis that might extend the duration of perfusion is truly of considerable clinical importance. Success in this regard may pave the way for the routine use of augmenting mediators in ex vivo perfusion. The rationale, nonetheless, remains equivocal in 
structure, process, and outcome but serves as fertile substrate to generate hypotheses and broaden the search for even more ways to extend perfusion in a quest, ultimately to increase the number of available organs for donationthe ultimate gift.

\section{References}

1. Hozain AE, O’Neill JD, Pinezich MR, Tipograf Y, Donocoff R, Cunningham KM, et al. Xenogeneic cross-circulation for extracorporeal recovery of injured human lungs. Nat Med. 2020;26:1102-13.

2. Takahashi M, Cheung H, Watanabe T, Zamel R, Cypel M, Mingyao Liu M, et al. Strategies to prolong homeostasis of ex vivo perfused lungs. J Thorac Cardiovasc Surg. 2021;161:1963-73.
3. Nakajima D, Watanabe Y, Ohsumi A, Pipkin M, Chen M, Mordant P, et al. Mesenchymal stromal cell therapy during ex vivo lung perfusion ameliorates ischemiareperfusion injury in lung transplantation. J Heart Lung Transplant. 2019;38:1214-23.

4. Koike T, Yeung JC, Cypel M, Rubacha M, Matsuda Y, Sato M, et al. Kinetics of lactate metabolism during acellular normothermic ex vivo lung perfusion. J Heart Lung Transplant. 2011;30:1312-9.

5. Cypel M, Yeung JC, Hirayama S, Rubacha M, Fischer S, Anraku M, et al. Technique for prolonged normothermic ex vivo lung perfusion. J Heart Lung Transplant. 2008;27:1319-25.

6. Yeung JC, Cypel M, Machuca TN, Koike T, Cook DJ, Bonato R, et al. Physiologic assessment of the ex vivo donor 406 lung for transplantation. J Heart Lung Transplant. 2012;31:1120-6.

7. Buchko MT, Stewart CJ, Hatami S, Himmat S, Freed DH, Nagendran J. Tota parenteral nutrition in ex vivo lung perfusion: addressing metabolism improves both inflammation and oxygenation. Am J Transplant. 2019;19: 3390-7.
See Article page 1963.

\section{Commentary: Maintaining the pHysiological equilibrium}

\author{
Alberto Benazzo, MD, and \\ Konrad Hoetzenecker, MD, PhD
}

A great potential of ex vivo lung perfusion (EVLP) lies in reconditioning grafts of an unacceptable quality so that they can be used for transplantation. In this regard, several approaches have been described in experimental studies, including the treatment of infected donor lungs with high-dose antibiotics, ${ }^{1}$ increasing endogenous interleukin10 production by gene therapy, ${ }^{2}$ and clearing a graft from hepatitis $\mathrm{C}$ virus. ${ }^{3}$ However, the clinical applicability of most of these approaches is limited by the inability of perfusing human allograft for a prolonged period of time. In the clinical routine, a 4- to 6-hour EVLP run can be performed safely, which usually allows a thorough quality

\footnotetext{
From the Department of Thoracic Surgery, Medical University of Vienna, Vienna, Austria.

Disclosures: The authors reported no conflicts of interest.

The Journal policy requires editors and reviewers to disclose conflicts of interest and to decline handling or reviewing manuscripts for which they may have a conflict of interest. The editors and reviewers of this article have no conflicts of interest.

Received for publication Aug 11, 2020; revisions received Aug 11, 2020; accepted for publication Aug 12, 2020; available ahead of print Aug 17, 2020

Address for reprints: Konrad Hoetzenecker, MD, PhD, Division of Thoracic Surgery,

Medical University of Vienna, Waehringer Guertel 18-20, 1090 Vienna, Austria

(E-mail: konrad.hoetzenecker@meduniwien.ac.at).

J Thorac Cardiovasc Surg 2021;161:1977-8

$0022-5223 / \$ 36.00$

Copyright (c) 2020 by The American Association for Thoracic Surgery

https://doi.org/10.1016/j.jtcvs.2020.08.032
}

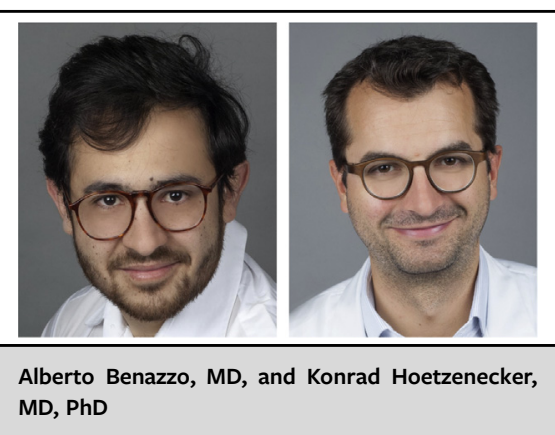

CENTRAL MESSAGE

Adaptions of current EVLP protocols are needed to be able to perfuse donor lungs for 24 hours and longer.

assessment of marginal organs; however, it is often too short to correct severe derangements of allografts.

In the article "Strategies to Prolong Homeostasis of Ex Vivo Perfused Lungs," Takahashi and colleagues ${ }^{4}$ explored 3 different modifications of the Toronto perfusion protocol in a pig EVLP model of 24 hours: (1) a continuous replacement of EVLP perfusate, (2) adding glucose and sodium to maintain perfusate osmolality, and (3) adding parenteral nutrition supplemented with amino acids and vitamins. The authors showed that all 3 protocols resulted in stable perfusion conditions for 24 hours, improved functional parameters of the grafts, and reduced inflammatory burden.

This paper highlights the necessity to develop more physiological EVLP protocols to be able to safely prolong 